\title{
Organização e intensificação do tempo de trabalho
}

\section{Ana Claudia Moreira Cardoso ${ }^{1}$}

Resumo: $\mathrm{O}$ artigo aborda as transformações sofridas pelo tempo de trabalho nas últimas décadas, considerando suas três dimensões: duração, flexibilidade e intensidade. As duas primeiras, concretas e mensuráveis e, portanto, mais visíveis para a sociedade, são frequentemente discutidas, negociadas e legisladas. Menos evidente, por outro lado, é a dimensão da intensidade, foco deste estudo. Num contexto em que os diversos aparatos organizacionais e de gestão têm como objetivo e consequência a intensificação do tempo de trabalho, trazer essa questão para o centro do debate é de fundamental importância para a compreensão do trabalho. Para isso, o estudo se apoia em análise bibliográfica articulada aos resultados da Enquete Europeia sobre Condições de Trabalho e tem, como ponto de partida, a reflexão sobre questões como: o que significa intensidade? Como ela se manifesta? Quais são suas causas e determinações? Quais são suas consequências? Por que está praticamente ausente do debate?

Palavras-chave: Tempo de Trabalho, Organização do Trabalho, Intensificação, Jornada, Saúde.

\section{Introdução}

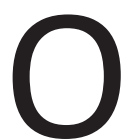

presente artigo $^{2}$ trata do tempo de trabalho e seu forte processo de transformação a partir dos anos 1980. O efeito mais perceptível desse movimento está na flexibilização do tempo de trabalho, com a implantação de novas formas de compensação da jornada e do aumento dos chamados tempos atípicos de trabalho. A fragmentação e individualização dos tempos de trabalho levam ao surgimento de uma pluralidade de novos tempos laborais, que se colocam, cada vez mais, em total assincronia com os outros tempos sociais - como o da família, do descanso, do lazer, da educação, etc. Menos visível, por sua vez, é o aprofundamento do processo de intensificação do tempo de trabalho, sobretudo a partir dos anos 1980 e 1990, quando se difundem novas mudanças tecnológicas, organizacionais e de gestão, que se somam às antigas manifestações (BOISARD et al, 2002). Em meio a essa profunda transformação, cuja compreensão permanece um grande desafio, a questão que se coloca é "Para onde vai o tempo de trabalho?"3.

A partir dessa indagação discutirei as atuais configurações do tempo de trabalho, considerando suas três dimensões: duração, distribuição - que inclui a flexibilidade - e intensidade (DAL ROSSO, 1996). Analisarei a relação entre tais
Recebido: 09.04.12 Aprovado: 16.03 .13

1. Assessora e formadora sindical no DIEESE - Departamento Intersindical de Estatística e Estudos Sócio-Econômicos e pesquisadora do CRESPPA

- Centre de Recherche Sociologique et Politique de Paris.

E-mail: anacmc2@ hotmail.com

2. Este texto é o resultado do pós-doutorado realizado na Universidade de Brasília, sob orientação do professor Sadi Dal Rosso, do trabalho que realizo no DIEESE (Departamento Intersindical de Estatística e Estudos Socioeconômicos), desde 1990 e do doutorado, realizado em regime de cotutela entre a USP e a Universidade de Paris VIII, que teve como foco o estudo das vivências temporais cotidianas de trabaIhadores.

3. "Para onde vai o tempo de trabalho" é o título do livro de Terssac e Tremblay (2000). 
dimensões, mas darei ênfase no fenômeno da intensidade do tempo de trabaIho. Isso porque, mesmo sendo uma questão tão presente e relevante no cotidiano dos trabalhadores brasileiros, ela raramente é foco de discussão, seja na teoria e na pesquisa acadêmicas, no processo de negociação coletiva ou mesmo na elaboração de leis e regulamentos. Por outro lado, o setor patronal tem criado diversas estratégias técnico-organizacionais que têm como objetivo a intensificação do tempo de trabalho, tanto no Brasil (DAL ROSSO, 2008), como em outros países (BOISARD et al, 2002). Além disso, a importância dessa discussão está no fato de a literatura especializada apontar indícios de que a elevação da intensidade do tempo de trabalho está diretamente relacionada ao crescimento das manifestações de adoecimento físico, psíquico e emocional dos trabaIhadores (ASKENAZY, 2005; DAL ROSSO, 2006; DAVEZIES, 2001; GOLLAC, 2005; SELIGMANN-SILVA, 2011).

Assim, a intenção da presente investigação é avançar no conhecimento de um tema seminal à reflexão da sociologia do trabalho, bem como propor subsídios para o debate sobre uma questão tão iminente e abrangente, mas ainda pouco discutida na sociedade brasileira. Para tal, o artigo se inicia tratando do tempo de trabalho no momento presente, com uma breve discussão sobre as dimensões da duração e da distribuição. A dimensão da intensidade é, então, apresentada em quatro focos: o que é a intensidade do tempo de trabalho; causas e determinantes da intensidade; manifestações da intensidade e consequências para o trabalhador.

\section{O tempo de trabalho na sociedade contemporânea}

A temática do tempo é tão antiga como fundamental para a compreensão do funcionamento das sociedades, visto ser um dos elementos estruturantes da sua constituição. O tempo é uma dimensão essencial da relação do homem com o mundo, o que torna sua discussão relevante, sobretudo em um momento de mudanças fundamentais na cultura temporal contemporânea (GROSSIN, 1991 e ZARIFFIAN, 2001). Não me refiro ao tempo como uma grandeza física, associada ao sequenciamento de eventos a partir de uma referência, mas do tempo social, isto é, do tempo como algo produzido, vivenciado e representado pelos sujeitos (GROSSIN, 1991).

Assim como o tempo, o tempo de trabalho é uma dimensão-chave para o entendimento das interações construídas entre os atores sociais, que, para além das relações vinculadas à organização das condições de trabalho e de emprego, exprime um sistema de valores, crenças, normas, leis, vivências, representações e poderes. Elementos esses que, por sua vez, influenciam e são 
influenciados pelo que podemos chamar de tempos de "não trabalho" (CARDOSO, 2009).

\subsection{Duração do tempo de trabalho}

A duração é a dimensão mais perceptível do tempo de trabalho (DAL ROSSO, 1996) e, por isso mesmo, a mais estudada no meio acadêmico, analisada em diversas pesquisas, sendo, também, foco da ação sindical e legislativa (CARDOSO, 2009). Nos últimos anos, após um período de estagnação da redução da duração/extensão do tempo de trabalho (DAL ROSSO, 1996), configura-se uma tendência mundial rumo à jornada semanal de 40 horas, de acordo com o estudo encomendado pela Organização Internacional do Trabalho (LEE et al, 2009). Neste estudo os autores observam que o nível de desenvolvimento tecnológico e os ganhos de produtividade têm permitido e pressionado para que essa redução se realize. No entanto, em que pese essa tendência, a redução da jornada não pode ser vista como resultado direto do crescimento econômico, pois estamos falando de um campo de extrema disputa entre trabalho e capital.

Neste documento, é ainda frisado que não se observa tendência à desregulamentação do tempo de trabalho e que, nos países em desenvolvimento, o papel da legislação segue sendo essencial para a garantia dos direitos dos trabalhadores, entre eles a redução da jornada, uma vez que a negociação coletiva ainda é incipiente e não abrange todos os trabalhadores.

Quando analisamos apenas para os países da União Europeia, a partir dos resultados da Pesquisa Europeia sobre Condições de Trabalho, vê-se que a duração média da semana de trabalho está diminuindo. Em 1991, a duração média foi de 40,5 horas, em 2000 reduziu-se para 38 horas e, em 2010, foi de 36,4 horas semanais. De acordo com o relatório do Eurofound (2011), essa redução está vinculada à redução do percentual de trabalhadores com jornada superior a 48 horas por semana, aumento no número dos que trabalham menos de 20 horas, bem como mudanças no processo de negociação coletiva e na legislação.

Como consequência, para os trabalhadores de muitos países, a questão da duração não é mais o problema central, no que diz respeito ao tempo de trabalho. Isso não significa, entretanto, que a questão esteja resolvida, dado que a necessidade da sua redução é permanente, em função do contínuo processo de inovação. Além disso, estamos falando em médias entre países, setores, sexo ou formas de contratação. Na Turquia, por exemplo, 71\% dos trabalhadores têm jornadas superiores a 40 horas, enquanto apenas 13\% dos trabalhadores na Finlândia trabalham acima de 40 horas. Por sua vez, são os homens que têm uma jornada de trabalho maior, quando considerado apenas o tempo de trabalho 
4. De acordo com Souto Maior (apud CATALDI, 2011), os juízes estão apresentando a questão do direito a "desconectar do trabalho". Há, também, o recente entendimento da Justiça de que o tempo associado ao trabalho em domicílio, através do telefone celular ou da internet, deva ser considerado como tempo de trabalho. remunerado, assim como são os trabalhadores por conta própria que apresentam jornadas maiores, bem como os que trabalham no setor industrial (EUROFOUND, 2011).

Outra evidência de que a questão ainda não está resolvida é dada pela resposta à questão da Enquete Europeia sobre Condições de Trabalho onde, apesar de $55 \%$ dos trabalhadores explicitarem que gostariam de manter a jornada de trabalho atual, 31\% afirmaram que gostariam de reduzi-la. O que demonstra que a disputa em torno da duração do tempo de trabalho permanecerá tanto na pauta sindical como na patronal. O capital mantém sua resistência, assim como pressiona para o aumento da jornada, explícita ou veladamente. Nos países onde há maior controle e fiscalização para a realização de horas extras, há forte pressão patronal pela eliminação dos limites impostos pela legislação para a realização da hora extra, sem a necessidade de solicitação aos órgãos governamentais (CALVETE et al, 2011).

Paralelo a esse movimento, nota-se uma ampliação velada do tempo de trabaIho, que, na maior parte das vezes, não é contabilizado como tempo à disposição do empregador e, por isso mesmo, não é remunerado. Cada vez maior é o tempo dedicado às tarefas levadas para casa que, muitas vezes, ocorre de maneira informal. Também as tecnologias da informação, como o celular, o computador portátil e a internet, servem tanto para acionar como controlar os trabalhadores a qualquer momento e em qualquer local (CARDOSO, 2009). Por isso mesmo, a Enquete Europeia, em 2010, inseriu uma nova questão, indagando sobre a frequência de demanda para o trabalho durante o tempo livre: $16 \%$ dos trabalhadores responderam que trabalharam, no tempo livre, uma ou duas vezes por semana e outros $16 \%$ foram chamados uma ou duas vezes por mês.

Caberia refletir, igualmente, sobre aqueles tempos nos quais os trabalhadores passam a buscar soluções para o trabalho, principalmente a partir da ênfase dada à participação, levando-os a permanecerem "plugados" no trabalho, mesmo estando distantes da empresa (HIRATA, 1996) ${ }^{4}$. Podemos nos questionar, ainda, sobre o tempo gasto com o deslocamento dos indivíduos da casa ao trabalho e o crescente tempo dedicado às atividades de qualificação. Todos esses tempos podem ser denominados como "tempos dedicados ao trabalho" (CARDOSO, 2009).

Assim, vê-se que o tempo de trabalho vai invadindo o tempo de "não" trabaIho, tornando a fronteira entre esses dois polos cada vez mais fluida (ZARIFIAN, 2001). Uma invasão que ocorre não apenas pela demanda para a realização de trabalho nos momentos de "não trabalho", de forma explicita ou implícita, mas também pela crescente flexibilização do tempo laboral, determinada pelas necessidades do capital, desorganizando o planejamento da vida dos 
trabalhadores e seus familiares, como veremos a seguir.

\subsection{Distribuição do tempo de trabalho}

Um dos elementos a contribuir para o aumento da intensidade está relacionado à forma como o tempo de trabalho é distribuído, seu grau de flexibilidade e, ainda, quem determina essa flexibilidade. A partir dos anos 1980, diversas mudanças foram adotadas pelo capital, em relação à distribuição do tempo de trabalho, com a intenção de torná-lo cada vez mais flexível e, assim, aumentar a capacidade de resposta rápida às variações do mercado, mesmo num contexto de demissão de trabalhadores (ALVES, 2011).

No Brasil, o resultado pode ser visto na nova forma de contabilizar e compensar o tempo de trabalho, que passa a ter o ano como referência e não mais o mês ou a semana, como originalmente previsto. Em alguns países, a referência, inclusive, passa a ser a vida ativa do trabalhador ${ }^{5}$. Assim, temos a anualização, a modulação (ou chamado banco de horas), a ampliação do tempo de trabalho em horários e dias atípicos, como finais de semana ou à noite, bem como uma maior demanda por hora-extra e sobreaviso.

Nesse processo de construção social de um tempo de trabalho muito mais flexível, o discurso do capital buscou identificá-lo com a possibilidade de maior liberdade para o trabalhador. Entretanto, vemos que, de uma forma geral, o tipo de flexibilização que vem sendo implementada tem sido orientada, unicamente, pela demanda da produção e não pelas necessidades dos trabalhadores (LINHART, 2005). Para estes, ser flexível passa a significar ser ágil em relação à demanda do capital, estar aberto às mudanças no curto prazo, assumir riscos continuamente e depender cada vez menos de leis e procedimentos formais. No lugar de maior liberdade, essa organização do tempo de trabalho impõe novas formas de controle, que são muito mais difíceis de serem percebidas e, portanto, negociadas.

Além disso, se o tempo de trabalho fica cada vez mais flexível, o mesmo acontece com os tempos de não trabalho, dado que a flexibilização tem impactos negativos tanto dentro como fora do local de trabalho; dentro, a consequência é o aumento da intensidade e fora, é a desorganização do tempo de não trabaIho. Como frisam Parent-Thirion et al (2007), a partir dos resultados da Enquete Europeia sobre Condições de Trabalho, os horários estáveis aumentam a satisfação em relação ao equilíbrio vida-trabalho, de modo que "os trabalhadores preferem efetuar o mesmo número de dias a cada semana ou o mesmo número de horas a cada dia, mais que um número variável de dias ou horas, e ter horas de chegada e partida fixas, mais do que variáveis". Também sublinham que a

5. Um exemplo é a Compte épargnetemps, instituída em 1994, pelo Governo Francês, em função da pressão dos empregadores para que os gerentes não tirassem férias. Mais tarde, ela foi estendida para todos os trabalhadores possibilitando o trabalho a mais e seu "depósito" numa conta poupança podendo ser utilizadas como repouso ou licença, no limite de cinco anos. A partir de 2005, essas horas também podem ser convertidas no tempo que falta para o trabalhador iniciar a aposentadoria, sendo retirado o limite de cinco anos para seu uso (CARDOSO, 2009). 
flexibilidade imposta é percebida de forma negativa por parte dos trabalhadores, porque ela é vista como uma ameaça à regularidade e à previsibilidade, sendo a semana de trabalho tradicional (40 horas, cinco dias por semana, de segunda a sexta-feira) "sentida como algo muito positivo" (PARENT-THIRION et al, 2007, p. 81). Ainda de acordo com os autores, as pessoas que declaram ter seu tempo de trabalho alterado com frequência explicitam maior insatisfação em relação ao equilíbrio vida-trabalho e, quanto mais uma mudança de horário é anunciada com pouca antecedência, maior a insatisfação.

No que se refere à configuração da distribuição do tempo de trabalho no contexto atual, a Enquete Europeia de 2010 revela que, depois de mudanças profundas ocorridas em anos anteriores, no sentido da flexibilização e de novas formas de distribuição do tempo, o horário de trabalho tradicional ainda segue sendo a norma para a maioria dos trabalhadores. Com efeito, $67 \%$ dos trabaIhadores pesquisados responderam que trabalham o mesmo número de horas por semana; $58 \%$ o mesmo número de horas por dia e $77 \%$ o mesmo número de dias na semana. Observa-se, ainda, uma queda no percentual dos que trabaIham em turno, dos que trabalham à noite e ainda dos que trabalham sábado ou domingo. Entretanto, mesmo com a estagnação do processo de flexibilização, ainda de acordo com a Enquete de 2010, apenas 30\% dos trabalhadores responderam que seu horário de trabalho adapta-se muito bem aos seus compromissos sociais, contra $33 \%$ em 2000.

Esse pequeno percentual pode estar vinculado às diversas dimensões do tempo de trabalho, demonstrando que a crescente flexibilização, as novas formas de distribuição do tempo de trabalho, bem como a invasão do trabalho durante o tempo livre, constituem fontes de descontentamento por parte dos trabalhadores, mesmo num contexto de redução da duração legal do tempo de trabalho. Além disso, não podemos esquecer que todas as mudanças no tempo de trabalho têm impactos profundos na organização e vivência dos tempos de não trabalho, ainda mais se considerarmos as consequências da intensificação.

\subsection{Intensidade do tempo de trabalho: um conceito em construção}

No que diz respeito à dimensão da intensidade do tempo de trabalho, algumas questões são recorrentemente ressaltadas. A primeira delas é que estamos diante de um conceito ainda em construção, dada a sua extrema complexidade, associada à variedade de causas e formas de manifestação (GOLLAC, 2005). Isto é, se a dimensão da duração e mesmo da distribuição são mais facilmente observadas, contabilizadas, analisadas e, por isso mesmo, objeto de negociação, nos mais diversos espaços, o mesmo não ocorre com a intensidade. 
Além disso, de acordo com Jégourel (2010), a intensidade é uma noção "maleável" e não fechada, em função de suas diversas formas de manifestação e, ainda, da sua proximidade com outras noções como produtividade, carga de trabalho, número de trabalhadores, horário de trabalho ou ritmo de trabalho. Outra noção muitas vezes associada à intensidade é a condição de trabalho. No entanto, a autora frisa que elas não podem ser tomadas como sinônimas, mesmo que esta última, frequentemente, seja determinante do grau de intensidade, ou seja, um componente da sua formação. Podemos ter, por exemplo, uma condição de extremo barulho, que não significa, por sua vez, intensidade do trabalho, explicitando que a intensidade não é exatamente uma condição de trabalho.

Por isso mesmo, quando se pensa na possibilidade de medir a intensidade do tempo de trabalho, Jégourel (2010) concluiu que só é possível determinar o que está em torno dela, mas jamais a própria intensidade, a partir da descrição das diversas características da atividade do trabalho, que têm como consequência a intensidade. Questiona, desse modo, a intenção de se estabelecer um conceito fechado sobre o que é intensidade, assim como foi feito para a questão da duração.

Considerando-se essa complexidade para se identificar a intensificação do tempo de trabalho, a segunda questão ressaltada pelos autores refere-se à necessidade de partirmos do trabalhador para compreendermos as causas, manifestações e consequências da intensidade, pois dele é exigido um empenho maior. Dal Rosso (2008) frisa que o empregador demanda do trabalhador tanto a elevação da quantidade da produção como a qualidade crescente do produto ou do serviço prestado, sendo, então, a intensidade entendida pelo autor como a quantidade de dispêndio das capacidades dos trabalhadores, isto é, da sua energia física, inteligência e cultura, bem como a socialização herdada. Também não se deve esquecer, sublinha o autor, a capacidade do trabalhador de conceber, criar e analisar, além da afetividade ao relacionar-se com as pessoas, bem como a mobilização e utilização das experiências adquiridas ao longo da vida. Sublinha Linhart (2005) que essa crescente demanda para os gastos de energia intelectual e psíquica não substitui o gasto de energia física, mas a este se acumula, tornando, por isso mesmo, o trabalho cada vez mais intenso.

A intensidade está, portanto, relacionada à "carga total de trabalho por unidade de tempo" (FERNEX, 1998, p. 13), o que explicita que não podemos tratar as dimensões do tempo de trabalho de maneira separada, dado que, na vivência temporal cotidiana do trabalhador, há uma relação de influência recíproca entre sua duração, distribuição e intensidade. Fernex (1998), assim como Jégourel (2010), frisa que é importante analisar o conjunto das condições e características do trabalho, ou seja, a tarefa, o posto de trabalho, o ambiente físico, 
os objetos a manipular, a postura, as relações entre os trabalhadores, destes com a chefia ou com os usuários, o grau de autonomia, enfim, todo o ambiente do trabalho. Devem-se considerar ainda, as características dos próprios sujeitos, ou seja, sexo, idade, formação, saúde, expectativas em relação ao trabalho, bem como o contexto macro no qual se desenvolvem as relações de trabalho.

Para Bártoli (1980, apud FERNEX, 1998, p. 16), a noção de carga de trabalho tem justamente o significado de dispêndio de energia física, mental e psicológica "(...) necessário à produção, pelo trabalhador, de certa quantidade de produtos, em condições reais da sua atividade". Finalmente, ressalta Fernex (1998) que temos que compreender a relação entre as exigências do posto de trabalho e as capacidades e possibilidades de reações dos indivíduos, num determinado ambiente de trabalho e contexto macro, como será discutido no item sobre as consequências da intensificação para a saúde do trabalhador.

Assim, no que se refere à dimensão da intensidade do tempo de trabalho, podese observar que a noção de esforço é enfatizada pelos diversos autores, assim como o faz Jégourel (2010, p. 9), ao sublinhar que a intensidade do tempo de trabalho pode ser definida como o "nível de esforço fornecido pelos trabalhadores durante o tempo de trabalho". Contudo, é importante lembrar que, diferentemente da dimensão da duração e da flexibilização do tempo de trabalho, não existe nada na legislação que defina o nível de esforço que o trabalhador deve ou não realizar durante seu tempo de trabalho, ou seja, qual o limite máximo ou mínimo. A única obrigação do trabalhador é "(...) colocar seu tempo de trabalho à disposição do empregador e nada é dito sobre a eficácia do trabalho fornecido" (idem).

Tal situação explicita a necessidade de se analisar melhor a dimensão da intensidade, considerando suas causas, formas de manifestação e consequências, para a construção de subsídios e conhecimentos que possibilitem a inclusão também dessa temática na agenda de discussão dos diversos atores sociais.

\subsubsection{Causas e determinantes da intensificação do tempo de trabalho}

Se a intensidade do tempo de trabalho significa o esforço físico, psíquico e mental dos trabalhadores, para dar conta das exigências do posto, durante o tempo de trabalho, a terceira questão ressaltada pelos autores refere-se às causas e determinantes do aumento desse esforço. Para compreendê-los - e retomando a discussão anterior -, devemos analisar o conjunto das condições e características do trabalho, isto é, o ambiente de trabalho, no contexto atual. Um dos caminhos possíveis é voltarmos à história, mesmo que de forma muito breve, e verificarmos como o trabalho e o tempo de trabalho estão sendo reorganizados. 
Na crise dos anos 1970, entre as ações do capital para superar a queda da demanda por produtos e serviços, bem como quebrar a resistência do movimento sindical, foram introduzidas diversas mudanças na organização e gestão do trabalho (DURANT, 2004). Um processo de demissão em massa dos trabalhadores foi realizado e, em relação àqueles que permaneceram empregados, foram criadas ferramentas de mobilização, flexibilização e intensificação do tempo de trabalho, bem como a redução da remuneração fixa e aumento da variável vinculada a metas (ALVES, 2011). Todas essas mudanças ocorreram num contexto de crescente insegurança e medo, por parte dos trabalhadores, em relação ao futuro e ao emprego.

Trata-se do Toyotismo, que surge no Japão, nos anos 1950, num contexto de mercado restrito e que, por isso mesmo, acabou por ser útil na crise de 1970, tendo como mote uma produção enxuta, flexível e tensa (DURAND, 2004). Produção esta marcada pela redução de estoques, prazos, defeitos, retrabalho, paradas do ciclo de produção, entre outros. Marcada, ainda, pela maior diversidade de produtos e serviços e maior capacidade de responder às flutuações do mercado. Essas metas deveriam ser atingidas, vale ressaltar, com o mínimo de trabalhadores, pois, de acordo com Ohno, a preocupação central é sempre como produzir mais com menos trabalhadores (ALVES, 2011). Para se atingir tais objetivos, o capital produziu um conjunto de novos valores, normas, processos, negociações, legislações, ferramentas, inovações e formas de gestão, isto é, uma nova construção social do trabalho e do tempo de trabalho, com reflexos importantes no tempo de não trabalho.

Claro que a intensidade do tempo de trabalho não começa com o Toyotismo, já sendo discutida por Marx (1985), ao frisar que, quando da conquista da jornada de 10 horas, esta já continha a mesma quantidade ou mais trabalho e dispêndio de força vital que uma jornada de 12 horas, em função da sua maior densidade e menos poros de inatividade. Está presente, também, no taylorismo e no fordismo. Entretanto, a partir dos anos 1970, há um investimento maior em tecnologias e novas formas de organização e gestão que resultam no aumento da intensidade do tempo de trabalho, possibilitando, como salientado por Dal Rosso (2008), a realização de mais trabalho por um mesmo trabalhador.

O atual processo de intensificação do tempo de trabalho, para Durand (2004), se dá não apenas pela maior velocidade na execução dos gestos, mas também pela redução de sua porosidade, em função da supressão dos tempos denominados pelo capital como mortos e vivenciados pelos trabalhadores como tempos de descanso e recuperação. Evidencia-se o procedimento de reduzir os tempos entre diferentes operações, a partir da reorganização do trabalho, prevendo-se uma atividade enquanto há a recuperação de outra ou, ainda, fazendo trabaIhar os diferentes membros do corpo ao mesmo tempo, em tarefas diferentes. 
Significa que cada minuto deve ser inteiramente ocupado, sem parada e sem descanso. O capital denomina esse arranjo de "posto de trabalho eficaz" (DURAND, 2004), mas, para o trabalhador, isso significa intensificação do tempo de trabalho e adoecimento.

Esse fluxo tenso e intenso da produção (DURAND, 2004) impõe, cada vez mais, uma multiplicidade de intervenções que os trabalhadores devem realizar rapidamente para não romperem a continuidade do fluxo produtivo, aumentando, progressivamente, a tensão e o tempo de trabalho. Fernex (1998) ressalta que a redução dos estoques, aliado ao número mínimo de trabalhadores, torna o processo de produção muito mais tenso, sobretudo pelo fato de as empresas adotarem a chamada "administração por estresse". Também a multifuncionalidade tem sido uma forma de organizar o trabalho para viabilizar o aumento da produção sem a contratação de trabalhadores (CARDOSO, 2009).

Além disso, ressalta Durand (2004) que a manutenção do fluxo tenso só pode ocorrer como resultado da ação laboral coletiva, como, aliás, já discutido por Marx, ao ressaltar que a cooperação permitia estender ou estreitar o tempoespaço, constituindo-se numa nova força produtiva social do trabalho (MARX, 1985). Sublinha Alves (2011, p. 38) que "na medida em que o comprometimento do trabalhador é estimulado pela pressão coletivamente exercida pela equipe de trabalho, temos, portanto, outro elemento da exploração do trabalhador pelo trabalhador".

A busca pelo fluxo regular de produção quantitativa foi estendida também à qualidade (GOLLAC, 2005), sendo criada uma ampla gama de normas a serem seguidas pelos trabalhadores, visando à redução dos defeitos e, consequentemente, do retrabalho (ALVES, 2011). Dessa forma, controla-se não apenas o tempo de produção, mas também como é produzido e quem produz, gerando extrema tensão e medo por parte dos trabalhadores.

Para que os trabalhadores aceitem ou que resistam o menos possível a essas mudanças, os capitalistas também buscam novas formas de gerenciá-los. Se, na lógica taylorista, a ideia era neutralizar as iniciativas dos trabalhadores e prescrever todas as tarefas, o Toyotismo tem outra estratégia. Como frisado por Alves, "no tocante ao controle do elemento subjetivo o toyotismo seria um taylorismo às avessas", isto é, se com Taylor o gesto físico mecanizou-se, deixando "livre" o cérebro, o Toyotismo cria uma unidade "orgânica entre ação e pensamento no local de trabalho" (2011, p. 62).

No discurso empresarial, que busca descaracterizar a relação de subordinação à qual os sujeitos estão submetidos, não se trata mais de trabalhadores, mas sim de colaboradores ou associados, mobilizando a "inteligência, afetividade e personalidade", em favor da empresa (LINHART, 2005, p. 14). Entretanto, 
caso a estratégia de envolvimento não seja totalmente eficaz, dado que a dinâmica de mobilização e envolvimento apoia-se essencialmente no par contribuição e retribuição (LACMAN \& SZNELWAR, 2004) - e nem sempre o trabalhador é retribuído ou se sente retribuído à altura de seu envolvimento -, diversas ações são implementadas pelo capital.

Logo, independentemente do nível de envolvimento dos trabalhadores, o estabelecimento de uma remuneração extra, de forma explícita, mas também o discurso a respeito da possibilidade de uma promoção, bem como da manutenção no emprego, implicitamente, em muito contribui para o esforço dos trabalhadores em atingirem as metas definidas pela empresa. Além disso, a fixação de metas possibilita "assegurar a percepção pelos trabalhadores de que seu esforço é reconhecido" (PINA \& STOTZ, 2011, p. 166).

Pina e Stotz (2011), em estudo com os trabalhadores em montadoras de veículos, explicitam a relação entre o sistema de remuneração variável, da Participação nos Lucros e Resultados (PLR), e o aumento da intensidade do tempo de trabalho. A ampliação da pressão e do comprometimento do trabalhador acaba sendo potencializada em função da sua responsabilização, não apenas em relação às metas assumidas, mas também e, sobretudo, em relação ao grupo de trabalho.

O estabelecimento de metas, juntamente com o trabalho em equipe, leva ao maior controle e competição entre os trabalhadores. Para Alves, a extrema intensificação do tempo de trabalho deve-se ao fato de o trabalhador tornar-se "seu próprio carrasco" (2011, p. 125). Isso porque a gestão por metas busca alterar as formas de subordinação do trabalho ao capital, com o deslocamento da vigilância minuciosa, realizado pelas hierarquias e os controles de tempo, para o controle baseado em metas e no trabalho em grupo. No contexto presente, em realidade, temos a convivência de novas e velhas formas de controle e, portanto, de pressão e tensão. Por isso mesmo, a gestão por metas ou objetivos tem sido comumente chamada de gestão "by stress" (CATALDI, 2011), contribuindo para o processo de intensificação do tempo de trabalho e, consequentemente, para o adoecimento dos trabalhadores.

A combinação de comprometimento com o grupo, desejo em aumentar a remuneração, ter uma promoção ou manter o emprego é tão grande que, para alcançar as metas de segurança, por exemplo, os trabalhadores escondem as doenças, assim como os pequenos acidentes (ASKENAZY, 2005). Dessa forma, a pressão exercida pelo capital para a redução das doenças e acidentes, dado que estes levariam à interrupção do fluxo de trabalho, ocorre não através de melhorias nas condições de trabalho, mas a partir de metas que acabam "forçando" os trabalhadores a esconderem seus problemas de saúde. 


\subsubsection{Manifestações da Intensidade}

Considerando-se a discussão realizada até o momento, onde a complexidade do conceito explicita-se em função da variedade de causas e determinantes da intensidade (GOLLAC, 2005), bem como a proximidade com outras noções (JÉGOUREL, 2010), o desafio que se coloca é captar a noção de intensidade. O indicador proposto por Bartoli (apud FERNEX, 1998) é a fadiga/cansaço como revelador da carga de trabalho suportada pelo trabalhador. De forma que as questões a serem analisadas devem possibilitar identificar as condições de trabalho que determinam essa fadiga, a partir da vivência e percepção daquele que suporta a carga de trabalho.

Fernex (1998) sublinha que as pesquisas sobre condições de trabalho na França e na Europa, entre elas a Enquete Europeia sobre Condições de Trabalho, têm permitido conhecer a intensidade do tempo de trabalho (carga total de trabalho relacionada a uma unidade de tempo), pois tratam "da descrição de um trabaIho real, tal como percebido por um trabalhador. Elas fornecem elementos de apreciação sobre as exigências do trabalho, as condições nas quais ele é exercido e a penosidade que ele pode resultar" (FERNEX, 1998, p. 26). Entretanto, ressalta o autor que, nesse processo de construção do conceito de intensidade do tempo de trabalho, não podemos deixar de considerar que, assim como as condições de trabalho são objeto de conflito social, as tentativas de avaliação dessas condições também serão objeto desse mesmo conflito. Afinal, não interessa aos empregadores a explicitação de que é a organização e gestão do trabalho a responsável pelo adoecimento do trabalhador.

Para melhor conhecer as formas de manifestação da intensificação nos diferentes setores, Valeyre (2001), a partir das respostas dadas às questões da Enquete Europeia sobre Condições de Trabalho, construiu quatro indicadores de pressão e intensidade: "industrial", "organizacional, de "mercado" e "eventual". 0 indicador denominado "industrial" caracteriza as situações onde o ritmo do tempo de trabalho é imposto por máquina, seja uma linha de produção, um fluxo de produtos ou ainda de serviços. O segundo indicador é o "organizacional", quando o tempo de trabalho está submetido a normas de produção, prazos e formas de controle. $\mathrm{O}$ tipo de pressão denominada "organizacional" está presente nos setores de comércio e serviço, assim como em algumas indústrias, tendo como características principais a flexibilidade interna do trabalho, como polivalência ou multifunção e variabilidade de horários de trabalho.

Quando os trabalhadores devem responder à demanda de usuários, Valeyre (2001) denomina essa modalidade de intensidade de "mercado". As pressões de mercado abrangem os setores de comércio e serviços, mas também aquelas indústrias marcadas pela forte concorrência e instabilidade em relação à 
demanda e expectativa dos clientes, em termos de variedade, qualidade e rapidez nas mudanças dos produtos e serviços. Há, ainda, um quarto tipo de indicador, chamado "eventual", que é específico da pressão sofrida por trabalhadores em empresas de processos contínuos, marcados pela vigilância das instalações e o tratamento de problemas com urgência.

Em sua discussão, Valeyre (2001) frisa que, às formas tayloristas e fordistas de intensificação do trabalho que perduram, vêm, todavia, somar-se novos tipos de pressão temporal, que se desenvolvem segundo a lógica industrial de mercado. Assim, as pressões dos três primeiros tipos ("industrial", "organizacional" e de "mercado") normalmente se acumulam, sobretudo nos últimos quinze anos, apesar de guardarem formas de manifestação diferentes. A lógica "industrial", por exemplo, engendra uma pressão forte e pouco flexível, mas, por outro lado, é estável e previsível; já a de "mercado" é mais flexível, porém menos previsível (BOISARD et al, 2002). Nesse sentido, observam os autores que os trabalhadores estão submetidos, cada vez mais, a um acúmulo de determinantes, que intensificam seu tempo de trabalho (GOLLAC, 2005).

É o que podemos verificar nos resultados da Enquete Europeia sobre Condições de Trabalho, onde o percentual de trabalhadores submetidos a mais de três fatores que determinam a intensidade do trabalho aumentou de 30,3\%, em 2000, para 33,4\%, em 2010. Houve uma redução da pressão advinda de máquinas ou movimentos de produto, passando de 21,4\%, em 1995, para 17,9\%, em 2010. Por outro lado, outras pressões aumentaram. Aquelas advindas da necessidade de atingir metas e objetivos definidos pelas empresas passaram de $30 \%$, em 2000, para $41 \%$, em 2010, assim como aumentou o percentual de trabalhadores que responderam trabalhar com prazos rígidos, passando de $50 \%$, em 1991 , para $63,8 \%$, em 2010. O ritmo definido por exigências diretas de pessoas, apesar de elevado, se mantém estável em torno de $70 \%$. Por sua vez, o controle direto exercido pela chefia cai de $36 \%$, em 1995 , para $34 \%$, em 2010 , e o ritmo dependente de colegas de trabalho aumenta de 37,4\% para 39,3\%, em 2010.

As interrupções das tarefas (para a realização de outra atividade definida como mais urgente) também são consideradas uma forma particular de intensidade do trabalho (BOISARD et al, 2002) e estão mais presentes nas organizações de "mercado", mas também nas "industriais", sendo normalmente causadas por demanda de clientes, colegas e chefes. Na Enquete de 2000, 70\% dos trabaIhadores declararam ter interrupções, sendo que, para $37 \%$, elas interferem no trabalho e, para $44 \%$, elas não têm nenhuma consequência, sendo que as mais perturbadoras são aquelas relacionadas a problemas na organização e mau funcionamento das máquinas. Ter que seguir normas de qualidade também é definido pelos autores (idem) como elemento indireto de intensidade, dado que a obrigação de respeitar as normas deixa a cadência mais difícil de realizar. 
Na Enquete de 2010, um percentual alto de trabalhadores - em torno de $75 \%$ respondeu que deve seguir normas de qualidade.

Outras questões tratadas pela Enquete Europeia sobre Condições de Trabalho ainda são utilizadas pelos autores (DAUBAS-LETOURNEUX \& THÉBAUD-MONY, 2002). Dentre elas, as relacionadas à organização do trabalho, aos fatores físicos do ambiente de trabalho, ao assédio moral e à formação. Também o grau de autonomia é considerado, seja em relação à possibilidade do trabalhador escolher a ordem de realização das tarefas, os métodos de trabalho, a cadência ou a velocidade da produção, seja com a realização das pausas, no momento em que deseja. Isso porque, conforme o Eurofound (2011, p. 5), "A promoção de maior autonomia - permitir aos trabalhadores decidirem como responder às exigências com que se deparam no decurso do seu trabalho - pode tornar as exigências do trabalho mais aceitáveis e promover o bem-estar".

\subsubsection{Consequências da intensidade do tempo de trabalho para o traba- Ihador}

Um quarto ponto que pode ser percebido nas leituras sobre intensidade diz respeito à relação entre esta e o aumento da penosidade do trabalho, em consequência do adoecimento físico, psicológico e mental dos trabalhadores (ASKENAZY, 2005). Dessa forma, evidencia-se a necessidade de captar as causas da fadiga/ cansaço no local de trabalho, como revelador da carga de trabalho suportada pelo trabalhador, mas também as consequências dessa situação para a saúde.

Nessa discussão, têm-se buscado, cada vez mais, explicitar a relação entre organização do trabalho, intensidade e saúde do trabalhador, como pode ser visto no resumo da Enquete Europeia sobre Condições de Trabalho:

A parte dos horários atípicos cresceu no período entre 19952000. A intensidade do trabalho sentida pelos trabalhadores também apresentou crescimento, em razão das mudanças na organização das empresas. As fortes pressões do ritmo são fontes de penosidade e de riscos. Eles são associados a uma percepção mais pessimista da relação entre trabalho e saúde. (CENTRE D’ÉTUDES DE L’EMPLOI, 2001, p. 1)

Não são poucos os autores que consideram a atual organização do trabalho como sinônimo de degradação das condições de trabalho (ASKENAZY, 2005; GOLLAC, 2005 e VALEYRE, 2006). São destacadas, também, questões relacionadas ao aumento da violência doméstica, dado o cansaço, irritação, medo e ansiedade; além do aumento da dependência química e do alcoolismo, 
assim como do burnout e o suicídio (SELIGMANN-SILVA, 2011). Askenazy (2005) questiona, inclusive, se podemos falar em uma nova forma de organização ou se seria, na realidade, uma desorganização do trabalho e do tempo de trabalho. Questiona-se, ainda, se essas novas práticas são naturalmente degradantes ou se é a maneira como elas estão sendo implantadas pelo capital, sem considerar a saúde e a segurança dos trabalhadores, que explica a degradação das condições de trabalho. Ainda de acordo com o autor, "Esta desorganização pode ser simplesmente transitória e, nesse sentido, as práticas inovadoras não seriam mais associadas à intensificação" (ASKENAZY, 2005, p. 221). Entretanto, ressalta que até o momento a exaustão física, psíquica e emocional é recorrente nas falas dos trabalhadores e não tem dado amostra de que estaria se reduzindo.

A forte pressão não é a única a causar o adoecimento do trabalhador, pois, como já visto, há outras dimensões que precisam ser consideradas comparativamente: a capacidade e controle do trabalhador sobre o próprio trabalho. A hipótese de Karasek (1979, apud ARAÚJO, 2003) é que uma forte pressão, com fraca autonomia/controle e ainda fraca sustentação social, constitui fator de risco, tensão e maior intensidade do trabalho, gerando insatisfação em relação à condição de trabalho e adoecimento. Logo, contribui para o adoecimento uma situação na qual o trabalhador se encontra confrontado com fortes exigências, mas dispõe apenas de uma pequena autonomia e controle no seu trabalho e ausência de condição de realizá-lo.

Em meio ao debate sobre a relação entre as novas formas de gestão e organização do trabalho, geradoras de maior intensidade, e suas consequências para a saúde do trabalhador, a própria noção de estresse foi sendo modificada. Se, antes, prevalecia o entendimento deste ser resultante apenas da relação entre as demandas e as capacidades do indivíduo, a nova noção explicita que a situação é estressante quando há um sentimento de desequilíbrio entre o que é demandado e os recursos disponíveis para responder à demanda, sejam eles cognitivos, de autonomia, apoio, tempo, etc. De forma que o estresse passa a ser visto não como o revelador da fragilidade dos indivíduos, mas como uma manifestação do mau funcionamento das empresas (INRS, 2010).

Nesse sentido, há certas situações de trabalho que são identificadas como potencializadoras do estresse e, consequentemente, do adoecimento. Entre elas, as referentes ao conteúdo do trabalho, tais como as fortes exigências quantitativas (carga de trabalho, pressão temporal, muita informação); qualitativas (precisão, qualidade, vigilância), dificuldades ligadas às tarefas (monotonia, ausência de autonomia, repetição, fragmentação) e os riscos inerentes à execução da tarefa (de vida, financeiro). Em relação à organização do trabalho, os elementos potencializadores são a falta de controle sobre as tarefas; imprecisão em relação às mesmas; dúvidas sobre a avaliação; contradição entre as exigências 
do posto; inadequação entre horário de trabalho e ritmo biológico, vida social e familiar; fluxo tenso; polivalência e instabilidade. No que diz respeito à relação de trabalho, esses elementos potencializadores são a falta de apoio, o autoritarismo e a ausência de participação. Há, ainda, causas relacionadas ao ambiente físico, bem como as relacionadas ao ambiente socioeconômico da empresa (INRS, 2010).

Vimos que muitos dos fatores desencadeantes do estresse e do adoecimento estão presentes nos novos modos do capital organizar o trabalho. Por isso mesmo, um percentual alto de trabalhadores relata algum tipo de doença. De acordo com a Enquete Europeia de 2005, dos 17 sintomas que aparecem na pesquisa, a maior parte dos trabalhadores assinalou de dois a seis, entre eles: dores nas costas, musculares, cansaço, estresse, dor de cabeça, irritabilidade, machucados, insônia, ansiedade, problemas na vista, na audição, na pele, dor no estômago, dificuldade respiratória, alergias e problemas cardíacos (PARENTTHIRION et al, 2007). Tais sintomas, de acordo com Daubas-Letourneux e Thébaud-Mony (2002), refletem a "hipersolicitação" dos trabalhadores expostos a prazos curtos, forte repetição, cadências elevadas e falta de tempo para realizar o trabalho.

Outro problema decorrente da intensidade do tempo de trabalho, de acordo com Boisard et al (2002), é a dúvida, por parte do trabalhador, entre atender aos objetivos/metas da produção e o desejo de preservar a saúde, pois a urgência os leva a adotar a maneira mais rápida de trabalhar, que nem sempre é a mais confortável ou a melhor para sua saúde e segurança. Contribui, ainda, para o adoecimento, o fato de muitos trabalhadores não revelarem seus processos de adoecimento ou os pequenos acidentes (ASKENAZY, 2005). Na Enquete Europeia sobre Condições de Trabalho de 2010 , quase $40 \%$ dos trabalhadores responderam que trabalharam mesmo estando doentes. A fala de um trabalhador explicita muito bem a relação entre intensidade, pressão, metas, medo de perder o emprego e adoecimento:

(...) Jogam com o medo... Há uma grande pressão para chegar ao objetivo de zero acidente de trabalho. As pessoas não declaram mais seus acidentes, pois se sentem investigadas, notadas, estigmatizadas. O que também faz mal é que temos metas em matéria de cadências, metas inatingíveis, pois não é possível manter essas cadências durante 8 horas. É necessário justificar porque não atingimos as metas e é preciso anotar tudo. Na prática, não é possível reduzir a dificuldade do trabalho e aumentar a produtividade se aproximando das metas. De um lado, dizem eles, segurança, e de outro, produtividade. Os funcionários têm a sensação que se não alcançarem as metas a empresa vai falir. Isso alimenta o medo... 
As pessoas são infelizes, mas não falam, pois têm medo. Se antes eles declaravam suas doenças profissionais, hoje eles já não o fazem. Um funcionário que declarou foi demitido. (MATHIEU \& GORGEU, 2009, p. 14)

Como salientam Lacman e Sznelwar (2004), o contexto de precariedade do emprego provoca uma estratégia defensiva de silêncio por parte de muitos trabalhadores, deixando livre o caminho para a intensificação do trabalho e o consequente aumento do sofrimento e adoecimento. Essa estratégia do silêncio também pode ser percebida no percentual relativamente baixo de trabalhadores que considera sua saúde e segurança em risco devido ao trabalho. . De acordo com a Enquete Europeia, o percentual está até mesmo diminuindo desde 2000: 31\% naquele ano, 28\%, em 2005, e 24\%, em 2010.

De acordo com Fernex (1998), muitos estudos têm mostrado que os trabalhadores tendem a subestimar a penosidade do trabalho, mesmo quando se trata de algo "mais" físico, como a perda da audição, por exemplo. Além disso, muitas vezes, o trabalhador não compreende a vinculação entre o adoecimento e o processo de trabalho (SELIGMAMN-SILVA, 2011). Outras vezes, ainda, predomina um discurso de que a culpa pelo adoecimento é do trabalhador, que é fraco, incapaz ou não observa as normas de segurança, assim como é culpa do trabaIhador ele não estar empregado ou qualificado.

\section{Considerações finais}

O foco principal deste artigo é a intensidade do tempo de trabalho, em função da sua relevância para o cotidiano dos trabalhadores e da sua escassez no debate brasileiro. Ao discutir o significado da noção de intensidade do tempo de trabalho, suas causas, manifestações e consequências, o objetivo é contribuir para sua compreensão e visibilidade. Afinal, quanto à percepção social, existe um contraste entre a dimensão da duração do tempo de trabalho, mais reconhecida pelo público, e a dimensão da intensidade, ainda pouco aparente.

Ao longo do texto, observou-se que, no que se refere à dimensão da duração do trabalho, há um movimento de convergência para a jornada de 40 horas semanais, apesar da grande dispersão ao se compararem diferentes países, setores, categorias profissionais ou tipos de contrato. Por outro lado e, paradoxalmente, há também uma ampliação velada da duração do tempo de trabalho. No que se refere à dimensão da flexibilidade, observa-se seu aumento, a partir dos anos 1980, com a criação e contínuo avanço dos chamados tempos atípicos de trabalho, bem como a anualização do tempo de trabalho que, para efeito de compensação e contabilização, passa a ter como referência o ano e não mais 
a semana ou o mês.

De acordo com os dados da Enquete Europeia sobre Condições de Trabalho de 2005 , em torno de $30 \%$ dos entrevistados responderam que gostariam de reduzir a jornada de trabalho, revelando que o tempo de trabalho ainda é foco de descontentamento por parte dos trabalhadores, mesmo que as dimensões da duração e da distribuição sejam objeto tanto da legislação como de regras definidas em negociação coletiva. Fenômeno que pode ser explicado pelo fato de ser um tempo que, cada vez mais, invade a vida para além do local de trabalho, implícita e explicitamente, tanto do ponto de vista quantitativo, a partir de horas de trabalho a mais e não programadas, como qualitativo, através do cansaço e do adoecimento.

Em relação à dimensão da intensidade do tempo de trabalho, dadas suas diversas causas, variadas formas de manifestação, vê-se que só é possível determinar aquilo que está em seu entorno, mas dificilmente a própria intensidade. Para tal, é necessário analisar o conjunto das condições do trabalho, que inclui uma ampla gama de elementos, tais como: as características da tarefa, do posto de trabalho, do ambiente físico, dos objetos a manipular e da postura. Também é fundamental cruzar tais informações com as características dos próprios sujeitos, bem como com suas expectativas em relação ao trabalho. É preciso, ainda, analisar as relações entre os trabalhadores, destes com a chefia ou com os usuários e, sobretudo, o grau de autonomia do trabalhador. Ou seja, para melhor compreender a intensidade do tempo de trabalho é necessário conhecer a relação entre as exigências do posto de trabalho e as capacidades e possibilidades de ação e reação dos trabalhadores, num determinado ambiente de trabalho, assim como, no contexto macro. Esse olhar rompe com a antiga percepção da intensidade vinculada apenas à extensão do tempo de trabalho ou ao ritmo e cadência da produção.

Para captar esse amplo leque de informações, uma segunda ressalva é importante: torna-se necessário partir do trabalhador, pois é ele quem faz o trabalho, dele é exigido um empenho maior ou menor para a sua realização. Assim, a intensidade é entendida como a quantidade de dispêndio das capacidades dos trabalhadores, tanto do ponto de vista físico, como psicológico e emocional. Todas as situações que exigem do trabalhador maior carga de trabalho, aumento de demanda e/ou pressão resultam na elevação do seu nível de esforço, da sua atenção e/ou dedicação. Logo, para analisar a intensidade do tempo de trabaIho, é necessário considerar a vivência do sujeito em relação à carga de trabaIho/nível de esforço, por um determinado período, num contexto organizado localmente e socialmente.

Um terceiro ponto, em torno do qual podemos organizar o debate atual, 
diz respeito às fontes determinantes que pressionam para a elevação do nível de esforço dos trabalhadores, durante o tempo de trabalho. As novas formas de organização do trabalho, implantadas pelo capital, estão na origem dessa intensificação, ao buscarem aumentar o fluxo da produção, sua variedade, sua capacidade de responder às flutuações do mercado, com um percentual cada vez menor de trabalhadores. Uma organização que pode ser adjetivada como enxuta e flexível, mas também como incerta e intensa.

Vimos que são inúmeras as fontes de intensificação do tempo de trabalho a que estão submetidos os trabalhadores: maior ritmo; maior densificação do tempo, com redução das pausas e das chamadas "porosidades"; multiplicação das tarefas; multifuncionalidade; prazos cada vez mais rígidos e curtos; interrupções frequentes de uma tarefa para realização de outra; necessidade de reação cada vez mais imediata e urgente; mudanças cada vez mais frequentes, que exigem mais tempo de aprendizado das novas tarefas e ampla gama de normas a serem seguidas pelos trabalhadores. Por sua vez, a gestão por objetivos ou metas tem sido sublinhada como umas das principais causas da intensificação do tempo de trabalho, ao pressionar os trabalhadores para a realização de mais trabalho (DAL ROSSO, 2008).

A forma como o capital vem gerindo e organizando o trabalho resulta, portanto, em crescente demanda de energia intelectual e psíquica dos trabalhadores, que não substituem o gasto de energia física, ao contrário, os dispêndios se acumulam. Dessa maneira, chega-se ao quarto ponto, que é a relação entre: a organização do trabalho, a intensidade do tempo de trabalho e a saúde e segurança do trabalhador; tanto no local de trabalho, como fora dele. Abordagem relevante, pois a atual organização tem sido apontada como fonte de crescente tensão, pressão, incerteza e intensificação do tempo de trabalho, contribuindo de forma relevante para a degradação das condições de trabalho.

No seu perfil contemporâneo a organização do trabalho e do tempo de trabalho é geradora, ainda, do aumento da penosidade, dada a crescente insegurança, aumento dos acidentes do trabalho, bem como das doenças físicas, psíquicas e emocionais. Para o capital, a gestão chamada "by stress", "time compression" ou "minimax" é vista como um instrumento de organização do trabalho, que tem como objetivo a intensificação e o aumento da produção. Por outro lado, para o trabalhador, esse tipo de gestão tem sido fonte de diversos problemas de saúde.

Assim, ao analisarmos as três dimensões do tempo de trabalho no contexto atual, podemos perceber o papel central que vem sendo ocupado pela intensidade do tempo de trabalho. Se, no século XVIII, eram as longas jornadas que contribuíam para o adoecimento, acidentes e morte dos trabalhadores, agora 
é a intensidade que ocupa esse espaço, sendo que, muitas vezes, há um acúmulo de determinantes. Parece plausível considerar que a duração elevada do tempo de trabalho e uma forte intensificação do mesmo são fenômenos exclusivos, dado que são formas diferentes de o trabalhador realizar uma carga de trabalho excessiva. Entretanto, em muitos países, como no Brasil, essas formas se acumulam, isto é, uma duração do tempo de trabalho elevada e um tempo de trabalho muito flexível, bem como intenso.

Finalmente, podemos dizer que, apesar do aumento no número de estudos em vários países, ainda são poucas as discussões em torno da relação entre: ambiente de trabalho, organização do trabalho, intensidade do tempo de trabalho e a saúde do trabalhador. Diversas são as razões para essa situação. Não apenas devido à própria dificuldade de se compreender como a intensidade se realiza no local de trabalho, de observá-la e distingui-la de outras manifestações, mas, sobretudo, porque realizar essa discussão significa questionar a organização e a gestão do trabalho, espaço este entendido pelo capital como privado, onde nem os trabalhadores e nem o Estado devem intervir.

Dessa forma, este estudo espera fornecer uma contribuição estratégica ao apontar a necessidade de incluir no debate, entre os diversos atores sociais, a relação entre a organização do trabalho e o processo de intensificação, considerando ainda as suas consequências para a saúde dos trabalhadores.

Abstract: The article discusses the transformations undergone by the working time in recent decades, considering its three dimensions: duration, flexibility and strength. The first two, concrete and measurable and therefore more visible to society are often discussed, negotiated and legislated. On the other hand, the focus of this study the dimension of intensity is less evident. In a context which the several organizational and managerial devices have as purpose and consequence the intensification of working time, analyzing this issue is of fundamental importance to understand work. For this purpose, this study is supported by bibliographical analysis articulated to the results of the "European Survey on Working Conditions" and has as a starting point the discussion of questions such as: What does the intensity of working time mean? How does this intensity manifest itself? What are its causes and determinations? Why is intensity practically absent from the debate.

Keywords: Working Time, Work Organization, Intensification, Working Hours, Health.

\section{Referências}

ALVES, Giovanni. Trabalho e subjetividade: o espírito do toyotismo na era do capitalismo manipulatório. São Paulo: Boitempo, 2011. 
ARAÚJO, Tânia Maria et al. "Estresse ocupacional e saúde: contribuições do Modelo Demanda-Controle". Ciência e Saúde, vol. 8, n 4, p. 12-42, São Paulo: 2003.

ASKENAZY, Philippe. "Sur les sources de l'intensification". Revue économique, Vol. 56, n², mars, p. 217-236, 2005.

BOISARD, Pierre et al. Temps e travail: l'intensité du travail. Fondation Européenne pour l'Amelioration des Conditions de Vie et de Travail. Luxembourg, 89 p, 2002.

CALVETE, Cássio. Redução da jornada de trabalho: uma análise econômica para o Brasil. Tese de Doutorado, Universidade Estadual de Campinas, 2006.

et al. "Redução da jornada de trabalho: uma luta do passado, presente e futuro". DIEESE, Nota Técnica $n^{\circ}$ 87, abril, 2010.

CARDOSO, Ana Claudia Moreira. "O tempo de trabalho na sociedade contemporânea". In: Martins, Heloisa Helena Teixeira de Souza \& Collado, Patrícia Alejandra (Org.). Trabalho e sindicalismo no Brasil e na Argentina. São Paulo: Hucitec, 2012.

et al. "Tempo de trabalho no Brasil: o negociado e o não negociado". XII Encontro Nacional da ABET. João Pessoa. Anais ABET, 2011.

Tempos de trabalho, tempos de não trabalho: disputas em torno da jornada do trabalhador. São Paulo: Annablume, 2009.

Tempos de trabalho, tempos de não trabalho: vivências cotidianas de trabalhadores. Tese de Doutorado, Faculdade de Filosofia, Letras e Ciências Humanas - USP, 2007.

CATALDI, Maria José. "Stress no meio ambiente de trabalho". 2a ed. São Paulo: LTr. Centre d'Études de l'Emploi - CEE. Contraintes de temps dans le travail et risques pour la santé en Europe. $\mathrm{n}^{\circ}$ 47, septembre, 2011.

CORRÊA, Daniela Lima \& Gilberto Tadeu. "Participação dos trabalhadores nos ganhos das empresas: lições da experiência internacional". Revista de Economia Contemporânea, Rio de Janeiro, vol. 10, n. 2: 357-388, 2006.

DAL ROSSO, Sadi. Mais trabalho: a intensificação do labor na sociedade contemporânea. São Paulo: Boitempo, 2008. 1996. São Paulo: LTr.

. "A jornada de trabalho na sociedade: o castigo de Prometeu", 
Direction de I'Animation de la Recherche, des Études e des Statistiques - DARES (2008) Les facteurs psychosociaux au travail: une évaluation par le questionnaire de Karasek de l'enquête Sumer 2003. Premières Synthèses: informations, mai, $n^{\circ} 22$. Paris.

DAUBAS-LETOURNEUX, Véronique. \& THEBAUD-MONY, Annie. "Organisation du travail et santé dans l'Union Européene". Fondation Européenne pour I'Amelioration des Conditions de Vie et de Travail - Eurofound, Luxembourg, 2002.

DAVEZIES, Philippe. "Charge de travail et enjeux de santé". Colloque: négocier la charge de travail entre performance organisation et conditions de travail. Paris, 2001.

DURAND, Jean Pierre. La chaîne invisible: travailler aujourd'hui: flux tendu et servitude volontaire. Paris: Seuil, 2004.

FERNEX, Alain. "Intensité du travail, définition, mesure, évolutions: premiers repérages". Etudes et Recherche, I'ISERES, n 169, février, Paris, 1998.

Fondation Européenne pour l'Amelioration des Conditions de Vie et de Travail - EUROFOUND. Evolução ao longo do tempo: primeiras conclusões do quinto Inquérito Europeu sobre as Condições de Trabalho. Luxembourg, 8 p, 2011.

GROSSIN, Willian. Pour une science des temps: introduction à l'écologie temporelle. Nancy: Octares, 1991.

HIRATA, Helena. "Introduction: le travail dês femmes: nouveaux partages, nouvelles divisions". In: Hirata, Helena \& Senotier Danièle. Femmes et partage du travail. Paris: Syros, p. 7-20, 1996.

Institut Nacional de Recherche et de Sécurité - INRS. Le Stress au travail. Dossier. Paris, 22p, 2010.

JEGOUREL, Marion. L'intensité du travail: enquêtes dans les industries chimique sur les tensions entre concept et activité. Tese de doutorado, Universidade de Provence, 2010.

LACMAN, Selma \& SZNELWAR, Laerte Idal. (Org.) Christophe Dejours: da psicopatologia à psicodinâmica do trabalho. Rio de Janeiro: Editora Fiocruz, 2004.

SANGHEON, Lee et al. Duração do trabalho em todo o mundo: tendências de jornadas de trabalho, legislação e políticas numa perspectiva global e comparada. Secretaria Internacional do Trabalho. Brasília: OIT, 2009.

DANIÈLE, Linhart. A desmedida do capital. São Paulo: Boitempo, 2005. 
MARX, Karl. O capital. 12. ed. São Paulo: Bertand Brasil, v. 1, 1985.

MATHIEU, René \& GORGEU, Armelle. O trabalho operário é sustentável? Uma ilustração na indústria automotiva na França. (mimeo) 31p

METZER, Jean Luc. "Mudança permanente: fonte de penosidade no trabalho?" In: Revista Brasileira de Saúde Ocupacional". Dossiê: O mundo contemporâneo do trabalho e a saúde mental dos trabalhadores - II. Vol.36, n¹23, jan/jun: 12 24, 2011.

PAOLI, Pascal \& MERLLIE, Damien. "Troisième enquête européene sur les conditions de travail 2000". Fondation Européenne pour l'Amelioration des Conditions de Vie et de Travail. Luxembourg, 72p, 2001.

PARENT-THIRION, Agnes et al. "Quatrième enquête européenne sur les conditions de travail". Fondation Européenne pour l'Amelioration des Conditions de Vie et de Travail. Luxembourg, 142p, 2007.

PINA, José Augusto. "Intensificação do trabalho e saúde dos trabalhadores na indústria automobilística: estudo de caso na Mercedes Benz do Brasil, São Bernardo do Campo". Tese de Doutorado, Escola Nacional de Saúde Publica Sergio Arouca - ENSO, 2012.

PINA, José Augusto \& STOTZ, Eduardo Navarro. "Participação nos lucros ou resultados e o banco de horas: intensidade do trabalho e desgaste operário". Revista Brasileira de Saúde Ocupacional. Dossiê: O mundo contemporâneo do trabalho e a saúde mental dos trabalhadores - II. vol.36, n¹23, jan/jun: 162-176, 2011.

SELIGMANN-SILVA, Edith. Trabalho e desgaste mental: o direito de ser dono de si mesmo. São Paulo: Cortez, 2011.

SELIGMANN-SILVA, Edith et al. "Saúde do trabalhador no início do século XXI". Revista Brasileira de Saúde Ocupacional. Dossiê: O mundo contemporâneo do trabalho e a saúde mental do trabalhador I, vol. 35, n 122, jul/dez, 2010.

SZNELWAR, Laerte Idal (Org.) Saúde dos bancários. São Paulo: Editora Gráfica Atitude Ltda, 2011.

TERSSAC, Gilbert Tremblay \& DIANE, Gabrielle. Où va le temps de travail? Paris: Octarès, 2000.

VALEYRE. Antoine. "Les Conditions de travail des salariés dans I'Union Européene à quinze selon fes formes d'organization". Travail et Emploi, n. 112, octobredécembre: 35-47, 2007. 
. "Conditions de travail et santé au travail des salariés de l'Union Européene: des situations contrastées selon les formes d'organisation". Centre d'Étude de l'Emploi, n 73, novembre. 49p, 2006.

"Le travail industriel sous la pression du temps". Travail et Emploi, n 86, avril: 127-149, 2001.

ZARIFIAN, Philippe. Temps et modernité: le temps comme enjeu du monde moderne. Paris: L’Harmattan, 2001. 